\title{
A Cryogenic Target for Compton Scattering Experiments at $\mathrm{HI} \gamma \mathrm{S}$
}

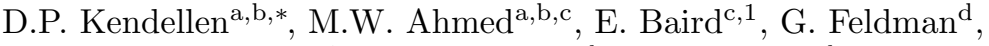 \\ N. Perreau ${ }^{\mathrm{e}, 2}$, P.W. Wallace ${ }^{\mathrm{a}, \mathrm{b}}$, H.R. Weller ${ }^{\mathrm{a}, \mathrm{b}}$ \\ a Triangle Universities Nuclear Laboratory, Durham, NC 27708, USA \\ ${ }^{b}$ Department of Physics, Duke University, Durham, NC 27708, USA \\ ${ }^{c}$ Department of Mathematics and Physics, North Carolina Central University, Durham, NC \\ 27707, USA \\ ${ }^{d}$ Department of Physics, George Washington University, Washington, DC 20052, USA \\ ${ }^{e}$ Department of Physics and Astronomy, University of North Carolina at Chapel Hill, \\ Chapel Hill, NC 27599, USA
}

\begin{abstract}
We have developed a cryogenic target for use at the High Intensity $\gamma$-ray Source $(\mathrm{HI} \gamma \mathrm{S})$. The target system is able to liquefy ${ }^{4} \mathrm{He}$ at $4 \mathrm{~K}$, hydrogen at $20 \mathrm{~K}$, and deuterium at $23 \mathrm{~K}$ to fill a $0.3 \mathrm{~L}$ Kapton cell. Liquid temperatures and condenser pressures are recorded throughout each run in order to ensure that the target's areal density is known to $\sim 1 \%$. The target is being utilized in a series of experiments which probe the electromagnetic polarizabilities of the nucleon.
\end{abstract}

Keywords: Cryogenic target, Liquid helium, Liquid deuterium, Compton scattering, Nucleon polarizabilities

\section{Introduction}

The Compton@HI $\gamma \mathrm{S}$ Collaboration is engaged in an experimental program to study nucleon electromagnetic polarizabilities using nuclear Compton scattering. The polarizabilities, $\alpha$ and $\beta$, encode the response of the nucleon's charged

\footnotetext{
${ }^{*}$ Corresponding author at: Triangle Universities Nuclear Laboratory, Durham, NC 27708, USA.

Email address: dpkendel@tunl.duke.edu (D.P. Kendellen)

${ }^{1}$ Present address: Hillsborough, NC, 27278, USA.

${ }^{2}$ Present address: Department of Mechanical and Aerospace Engineering, North Carolina State University, Raleigh, NC 27695, USA.
}

Preprint submitted to Nuclear Inst. and Methods in Physics Research, A September 20, 2016

(C) 2016. This manuscript version is made available under the Elsevier user license http://www.elsevier.com/open-access/userlicense/1.0/ 
constituents to external electric and magnetic fields. They characterize fundamental nucleon structure properties and provide a means to test various theoretical approaches to low-energy quantum chromodynamics (QCD) 11. Compton scattering from nuclei is a viable tool to extract electromagnetic (EM) polarizabilities. For example, proton EM polarizabilities have been extracted by a global fit to Compton scattering data from hydrogen targets. In the absence of a free neutron target, the neutron polarizabilities have been extracted using an effective-field-theory fit to Compton scattering data from the deuteron. Data taken with a ${ }^{4} \mathrm{He}$ target could encourage the extension of the theoretical framework to higher- $Z$ nuclei. Future measurements are also planned to extract neutron polarizabilities from ${ }^{3} \mathrm{He}$ Compton scattering.

These elastic Compton scattering processes have small cross sections, $\sim 10$ $100 \mathrm{nb}$. In order to achieve statistical uncertainties below $3 \%$ in a reasonable amount of time ( $\sim 300$ hours) with the available beam intensities on target $\left(\sim 10^{6}-10^{7} \gamma / s\right)$, dense liquid targets are necessary. To this end, we have con20 structed a single cryogenic target, cooled by a cryocooler, capable of liquefying hydrogen $\left(\mathrm{LH}_{2}\right)$, deuterium $\left(\mathrm{LD}_{2}\right)$, and ${ }^{4} \mathrm{He}(\mathrm{LHe})$. Cryocooler-based $\mathrm{LH}_{2}$ and $\mathrm{LD}_{2}$ targets have been used in years past at facilities worldwide (e.g., Refs. [26]). The $\mathrm{HI} \gamma \mathrm{S}$ Cryogenic Target incorporates features from these designs, but it is unique due to the fact that the same apparatus is used to liquefy not only ${ }_{25} \mathrm{D}_{2}$ and $\mathrm{H}_{2}$, but also ${ }^{4} \mathrm{He}$.

The HI $\gamma \mathrm{S}$ facility, located on the campus of Duke University and operated by Triangle Universities Nuclear Laboratory (TUNL), uses Compton backscattering of free-electron laser light to produce nearly-monoenergetic $\gamma$-ray beams at energies in the range of $1-100 \mathrm{MeV}$. The present set of measurements on deuterium and ${ }^{4} \mathrm{He}$ employs beams with energies of $60-85 \mathrm{MeV}$. Scattered photons are detected by the $\mathrm{HI} \gamma \mathrm{S}$ NaI Detector Array (HINDA), a set of eight $\mathrm{NaI}$ detectors which surround the cryogenic target. Each detector has a $25.4 \mathrm{~cm}$ diameter $\times 25.4 \mathrm{~cm}$ long core crystal and a segmented, annular NaI shield for cosmic-ray rejection. 
Table 1: Properties of the target liquids $[7,8] . T_{b}$ is the boiling point at $P=$ $1 \mathrm{~atm}, T_{\mathrm{tr}}\left(P_{\mathrm{tr}}\right)$ is the triple point temperature (pressure), $T_{\mathrm{c}}\left(P_{\mathrm{c}}\right)$ is the critical temperature (pressure), and $L$ the latent heat of evaporation at $T_{b}$. The " $n$-" for $\mathrm{D}_{2}$ and $\mathrm{H}_{2}$ denotes normal ortho-para composition.

\begin{tabular}{ccccccc}
\hline Target & $T_{\mathrm{b}}(\mathrm{K})$ & $T_{\mathrm{tr}}(\mathrm{K})$ & $P_{\mathrm{tr}}(\mathrm{atm})$ & $T_{\mathrm{c}}(\mathrm{K})$ & $P_{\mathrm{c}}(\mathrm{atm})$ & $L\left(\mathrm{~kJ} \mathrm{~L}{ }^{-1}\right)$ \\
\hline${ }^{4} \mathrm{He}$ & 4.2 & - & - & 5.20 & 2.24 & 2.56 \\
$n-\mathrm{H}_{2}$ & 20.4 & 13.95 & 0.07 & 33.1 & 12.8 & 31.8 \\
$n-\mathrm{D}_{2}$ & 23.3 & 18.69 & 0.17 & 38.3 & 16.4 & 50 \\
\hline
\end{tabular}

\section{Description of the cryogenic target}

A schematic and photo of the cryogenic target are shown in Fig. 1. The main components include: a cryocooler which provides refrigeration down to $3.2 \mathrm{~K}$, a Kapton target cell, and a vacuum can with thermal radiation shields to isolate the system from room temperature.

\subsection{Cryocooler and condenser}

The refrigerator is a $4 \mathrm{~K}$ Gifford-McMahon cryocooler with $1.5 \mathrm{~W}$ of cooling power at $4.2 \mathrm{~K}^{3}$ It consists of two components: the cold head (Item 1 in Fig. 1) and an external compressor. Cooling is provided by compression and expansion of high-purity helium gas in a closed loop. There are two expansion stages: the

45 first typically operates at $30-35 \mathrm{~K}$ and the base temperature of the second stage is $3.2 \mathrm{~K}$. This is sufficient to liquefy ${ }^{4} \mathrm{He}$, which has a $1 \mathrm{~atm}$ boiling point of 4.2 K. Properties for all three target liquids are shown in Table 1.

When filled with LHe, the target can operate over $3.2-5.2 \mathrm{~K}$, constrained by the base temperature of the cryocooler and the critical point of LHe. In ${ }_{50}$ practice, we run at the lower end of the range to (a) increase the liquid density and thus the target thickness and (b) protect the cell by keeping pressures

\footnotetext{
${ }^{3}$ Sumitomo Heavy Industries RDK415-D2
} 

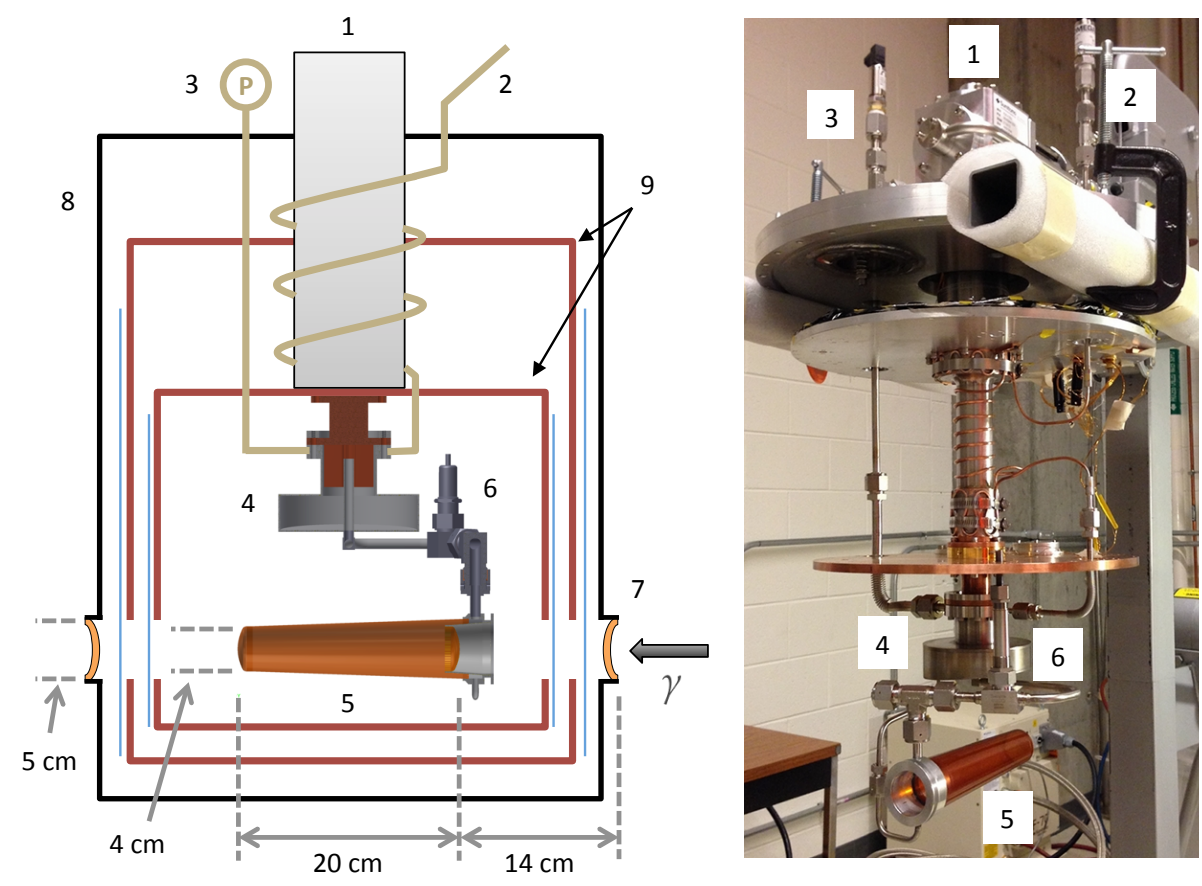

Figure 1: Schematic and photo of the cryogenic target. Components include: the cryocooler (1), room-temperature gas inlet (2), vent line with pressure gauge (3), condenser (4), Kapton cell (5), Full/Empty valve (6), Kapton windows (7), vacuum can (8), and thermal radiation shields with aluminized Mylar superinsulation (9). Items 7-9 have been removed in the photo, as has the actuator rod for the Full/Empty valve. 
$\leq 2$ atm. When filled with $\mathrm{LD}_{2}$ or $\mathrm{LH}_{2}$, the physical limits on the temperatures are set by the triple points and critical points given in Table 1 . For $\mathrm{LD}_{2}$, this corresponds to 18.7-38.3 K. The liquid is kept above the triple point to avoid freezing deuterium in the fill or pressure relief lines. We also choose to operate above $1 \mathrm{~atm}$ to prevent air from leaking into the system and freezing in the lines. As with LHe, we keep the pressure in the cell $\leq 2$ atm. With these constraints, the range for $\mathrm{LD}_{2}$ running is $24-26 \mathrm{~K}$. Applying the same restrictions to $\mathrm{LH}_{2}$ yields an operating range of $21-23 \mathrm{~K}$.

There are two cartridge heaters inserted into a copper block on the second stage of the cryocooler for operating above $3.2 \mathrm{~K}$. A proportional-integralderivative (PID) controller ${ }^{4}$ regulates the temperature. The control thermometer $5^{5}$ is inserted into the same copper block as the heaters. Holding the second stage at $24 \mathrm{~K}$ requires $23 \mathrm{~W}$ of heater power.

To liquefy the desired target material, we begin by sending room-temperature gas to an inlet at the top of the cryostat. Once inside, the gas exchanges heat with the two stages of the cold head. The heat exchangers consist of a $\mathrm{Cu}$ tube with an inner diameter of $1.7 \mathrm{~mm}$, bent into a serpentine shape and soft soldered to two $\mathrm{Cu}$ plates. The plates are attached to the first and second stages of the cryocooler with hose clamps. After passing through the heat exchangers, the precooled gas enters a condensing volume (Item 4 in Fig. 1) where it condenses onto a series of $\mathrm{Cu}$ fins and drips down into a fill line leading to the target cell.

\subsection{Target cell}

The target cell is $20 \mathrm{~cm}$ long with $4 \mathrm{~cm}$ diameter end caps and a volume of $75 \approx 285 \mathrm{~cm}^{3}$ (see Figs. 1 and 2 for sectional views). The body is the frustum of a cone formed from a single sheet of $0.125 \mathrm{~mm}$ Kapton, glued along a seam at the top with epoxy ${ }^{6}$ The end caps are made from the same $0.125 \mathrm{~mm}$ thick Kapton. An aluminum base piece at one end of the cell supports the cone, the

\footnotetext{
${ }^{4}$ Lake Shore Model 335

${ }^{5}$ Lake Shore DT-670B-CU

${ }^{6} 3 \mathrm{M}$ Scotch-Weld DP190 Gray
} 
upstream Kapton end cap, and the inlet/outlet ports. The base piece has a the condenser flows down a fill line and enters the cell through the inlet port at the bottom. The liquid is maintained at its saturated vapor pressure and is subjected to background heating inside the cryostat. Any bubbles that form float to the top of the conical body and then slide along the slanted top seam to back up to the $\mathrm{Cu}$ fins in the condenser. It recondenses and drips back down into the fill line and target cell. This convective loop between the cell and the condenser efficiently carries off heat from the liquid.

\subsection{Full/Empty valve}

90 If we were to simply boil off the liquid, it would take 1-2 hours to reliquefy and return to "full" mode. To reduce down time, the cryogenic target includes a valve to switch between two modes: "Full" with liquid in the cell and "Empty" where the liquid is stored in a reservoir and only cold gas remains in the cell.

In Full mode, boil-off vapor exits the cell and returns to the $\mathrm{Cu}$ condensing fins. Closing the Full/Empty valve (Item 6 in Fig. 1) blocks this path and causes pressure to build on the cell's outlet. The rising pressure eventually forces the liquid back through the fill line and into a reservoir below the condenser (Item 4 in Fig. 1) so that only cold vapor remains in the cell. We use a heater, a accelerate this process. Applying $630 \mathrm{~mW}$ of power empties the cell of LHe in 10 minutes. To refill the cell, we open the valve and liquid flows down from the reservoir within a few seconds.

\subsection{Vacuum can, heat shields, and beam windows}

The cryocooler, condenser, and cell are enclosed in a custom aluminum vac-

uum can. A turbomolecular pump keeps the apparatus under high vacuum $\left(\approx 10^{-6}\right.$ Torr $)$ to mitigate the heat load from residual gas accommodation. 


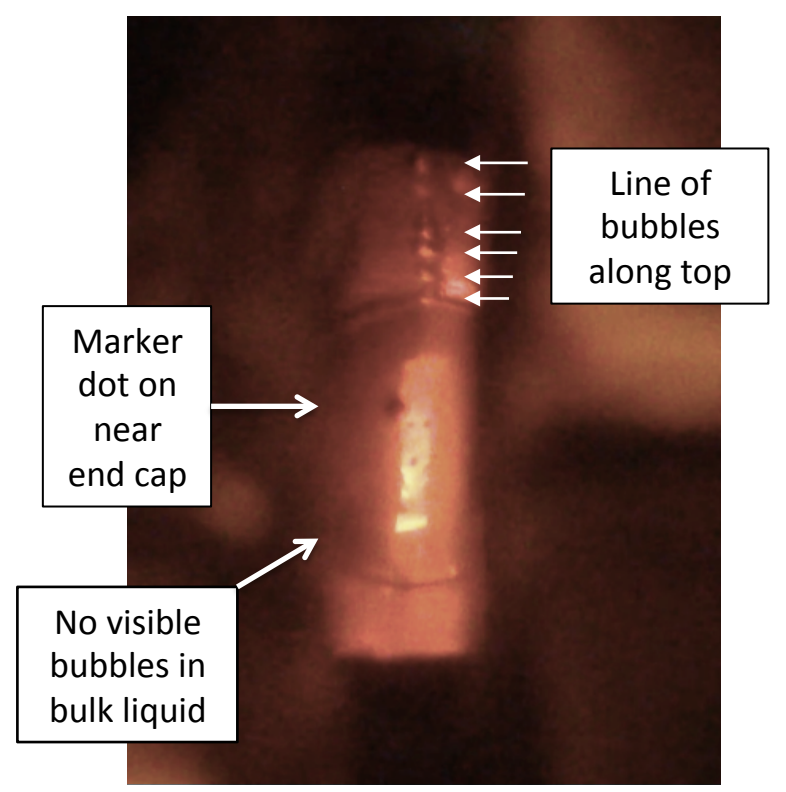

(a)

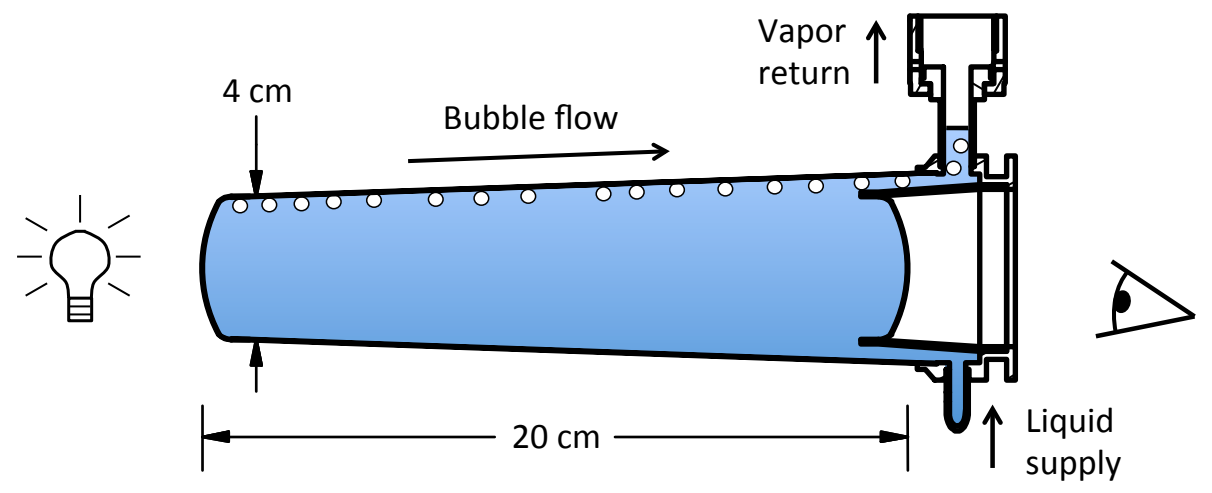

(b)

Figure 2: Observing bubbles in LHe. (a) Photo of the liquid, taken while looking through the beam window and slits in the multilayer insulation (MLI). When the cell is full, bubbles appear at the top of the cell and flow to the outlet in a straight line. There are no visible bubbles in the body of the cell. (b) Illustration of the viewing angle in the bubbling photo. A flashlight illuminates the cell from the opposite end. Distances between the cell and flashlight/eye symbols are not to scale. 


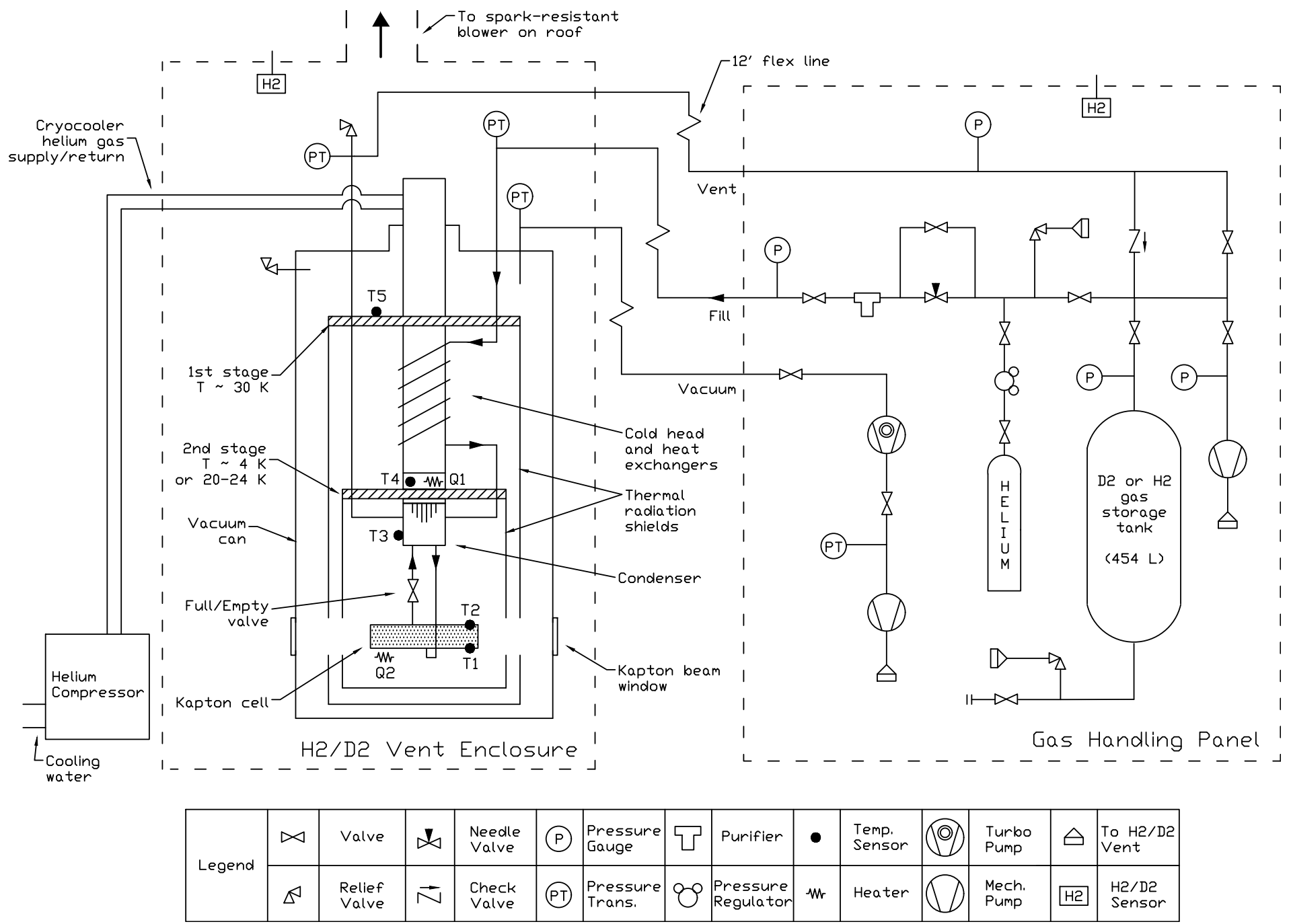

Figure 3: Piping and instrumentation diagram of the cryogenic target system. 
Two thermal radiation shields, one attached to each stage of the cryocooler, reduce radiative heating. They are made from $1 \mathrm{~mm}$ thick aluminum sheets and wrapped in several layers of aluminized Mylar superinsulation. To cut down on conductive heat loads, we used thin-walled stainless steel tubes and small-diameter phosphor bronze electrical leads to connect room-temperature components to the low temperature stages.

Photons entering and exiting the target encounter various materials in the Compton experiments. As depicted in Fig. 1, the incoming beam passes through Kapton windows on the vacuum can, superinsulation-covered holes in the two heat shields, Kapton end caps on the target cell, and the cryogenic liquid. The beam windows are constructed of the same $0.125 \mathrm{~mm}$ thick Kapton as the cell. Scattered photons pass through two $1 \mathrm{~mm}$ thick aluminum heat shields, several thin layers of aluminized Mylar, and the $3 \mathrm{~mm}$ aluminum wall of the vacuum can. Photons with energies of 65-85 MeV exiting through these layers are attenuated by $<5 \%$, as estimated using mass attenuation coefficients from Ref. 9 .

\subsection{Gas handling system}

The system's piping and instrumentation diagram is shown in Fig. 3. During operation, it is important to keep the target gases free of contaminants in order to avoid freezing blockages inside the fill and vent lines (Items 2 and 3 in Fig. 1), which could potentially halt the filling process or obstruct pressure relief paths. We start with $99.999 \%$ pure $\mathrm{H}_{2}, \mathrm{D}_{2}$, or $\mathrm{He}$ gas and send it through a roomtemperature purifier ${ }^{7}$ filled with molecular sieve before it enters the cryostat.

The gas handling system includes a storage tank for recovering the supply at the end of a run. This tank is also part of the safety system for operating with flammable gases. The automated response to most hazardous conditions is to turn off the cryocooler so that the liquid will evaporate back into the storage tank via the vent line, while the $\mathrm{H}_{2}$ or $\mathrm{D}_{2}$ remains isolated from air.

\footnotetext{
${ }^{7}$ Matheson $450 \mathrm{~B}$
} 


\section{Areal densities and uncertainties}

The target's areal density, or thickness, $\kappa$ is given by:

$$
\kappa=\frac{\rho t N_{\mathrm{A}}}{M},
$$

where $\rho$ is the liquid density, $t$ the length of the cell, $N_{\mathrm{A}}$ is Avogadro's number, and $M$ the molar mass. Multiplying by an additional factor of two is required for $\mathrm{D}_{2}$ or $\mathrm{H}_{2}$ to covert from molecules $/ \mathrm{cm}^{2}$ to target nuclei $/ \mathrm{cm}^{2}$. Target thicknesses for all three liquids are given in Table2. (Note: Although the LHe target is not as thick as the $\mathrm{LD}_{2}$ or $\mathrm{LH}_{2}$ targets, it actually counts faster since the elastic Compton scattering cross section scales as $\sim Z^{2}$ in the energy range of interest.)

The uncertainty in the areal density is determined by the respective uncertainties in the cell length and the liquid density:

$$
\frac{\Delta \kappa}{\kappa}=\sqrt{\left(\frac{\Delta t}{t}\right)^{2}+\left(\frac{\Delta \rho}{\rho}\right)^{2}} .
$$

Each term under the square root in Eq. 2 is made up of several constituent uncertainties. The uncertainty in the cell length includes the uncertainties in the following: length measurements performed at room temperature $(0.2 \%)$, thermal contraction $(0.1 \%)$, and the degree to which the pressurized cell flexes against vacuum $(0.8 \%)$. For the liquid density, uncertainties include the following: thermometer uncertainty $(<0.1 \%)$, temperature stability $(<0.1 \%)$, bubbling $(<0.1 \%)$, and temperature gradients $\left(0.7 \%\right.$ for $\mathrm{LHe} ; 0.1 \%$ for $\mathrm{LD}_{2}$ and $\mathrm{LH}_{2}$ ). For $\mathrm{LD}_{2}$ and $\mathrm{LH}_{2}$ there are also density fluctuations due to orthopara conversion (negligible for $\mathrm{LD}_{2}$ and $0.2 \%$ for $\mathrm{LH}_{2}$ ). The uncertainties in the liquid density are discussed in detail in Sections 4 and 5 .

Combining the above, the total uncertainties in target thickness are $1.1 \%$ for $\mathrm{LHe}, 0.8 \%$ for $\mathrm{LD}_{2}$, and $0.9 \%$ for $\mathrm{LH}_{2}$. These are slightly lower than the other systematic uncertainties in the experimental setup, including the flux monitoring system $(\approx 3 \%)$, detector resolution $(\approx 3 \%)$, etc. All of these contribute to the total systematic uncertainty in the measured cross sections. 
Table 2: Liquid densities at $P=1 \mathrm{~atm}[7]$ and target thicknesses for the $20.1 \mathrm{~cm}$ long cell. The " $n$-" for $\mathrm{D}_{2}$ and $\mathrm{H}_{2}$ denotes normal ortho-para composition.

\begin{tabular}{cccc}
\hline Target & $T(\mathrm{~K})$ & $\rho\left(\mathrm{g} / \mathrm{cm}^{3}\right)$ & $\kappa\left(\times 10^{23}\right.$ nuclei $\left./ \mathrm{cm}^{2}\right)$ \\
\hline${ }^{4} \mathrm{He}$ & 4.2 & 0.125 & 3.78 \\
$n-\mathrm{H}_{2}$ & 20.4 & 0.071 & 8.51 \\
$n-\mathrm{D}_{2}$ & 23.3 & 0.164 & 9.85 \\
\hline
\end{tabular}

\section{LHe Operation}

We carried out our initial tests of the cryogenic target using helium, which has less stringent safety requirements than flammable $\mathrm{H}_{2}$ or $\mathrm{D}_{2}$. Liquefying helium also pushes the limits of the refrigerator in cooling power and base temperature. Over several test runs, we liquefied helium and filled the target cell at temperatures ranging from $3.2-4.2 \mathrm{~K}$.

\subsection{Liquefaction tests and vapor pressure measurements}

During liquefaction, we observed the liquid level through the beam windows and $5 \mathrm{~mm}$ wide slits in the superinsulation, from the perspective shown in Fig. 2 Temperatures were measured using a factory calibrated thermometer 8 with an uncertainty of $\pm 6 \mathrm{mK}$ at $4 \mathrm{~K}$. Pressures were monitored with a transducer ${ }^{9}$ at the room-temperature end of a direct line to the condenser (inner diameter of $7.7 \mathrm{~mm})$.

As discussed in Section 3 it is important to measure the liquid temperature accurately, since uncertainties in liquid density contribute to the uncertainty in the target thickness. To cross-check the thermometer's factory calibration, we recorded the pressures and temperatures in the cell and compared them to values for the saturated vapor pressure (SVP) of liquid helium from Ref. [10. Fig. 4

\footnotetext{
${ }^{8}$ Lake Shore CX-1050-SD-HT-1.4L

${ }^{9}$ Omega PX319-050AV
} 
displays these measured pressures and temperatures during the filling process. First the cell was cooled with a small amount of helium gas inside. This gas facilitated heat transfer between the cell and condenser. As the cell cooled below $4 \mathrm{~K}$, we added more gas though a needle valve (see Fig. 3). The incoming gas was precooled, but not perfectly, so the temperatures in the condenser and cell began to rise. Once the pressures and temperatures approached the SVP curve and settled near $3.6 \mathrm{~K}$ and $8-9$ psi, the cell began filling with liquid. After confirming the cell was full by visual observation, we closed off the helium supply. This removed the heat load from incoming gas and the liquid cooled to the cryocooler's base temperature of $T_{\text {cell }} \approx 3.1 \mathrm{~K}$ (where $P_{\mathrm{SVP}}=4 \mathrm{psi}$ ). With liquid in the cell, there is excellent agreement between the $(T, P)$ pairs and the SVP curve.

The total time to fill the cell depends upon the mass flow rate of the incoming room-temperature gas. Since the incoming gas is not perfectly precooled, sending it in at a higher rate exhausts the cooling power of the cryocooler at a given temperature and thus increases temperatures in the condenser and cell. We can control the flow rate manually to liquefy at condenser and cell temperatures anywhere in the range of $3.2-5.2 \mathrm{~K}$.

In Fig. 4, when liquefying at 3.6-3.7 K, it took just under 2 hours to fill the cell. In subsequent tests at $4.2 \mathrm{~K}$, it took 1 hour to fill the cell, for a fill rate of $0.29 \mathrm{~L} / \mathrm{h}$. We could improve upon this liquefaction rate by developing more efficient heat exchangers. As a benchmark, at $4.2 \mathrm{~K}$ and $0.97 \mathrm{~atm}$, SchmidtWellenburg and Zimmer report a rate of $0.44 \mathrm{~L} / \mathrm{h}$ using the same model of cryocooler, but with optimized heat exchangers [1]. For our application, though, there is no particular rush to complete the initial liquefaction. After filling, the same $0.29 \mathrm{~L}$ of liquid is held in the apparatus throughout the run.

\subsection{Temperature stability}

Following the initial liquefaction tests, we performed a week-long target commissioning run with the $\gamma$-ray beam and acquired 54 hours of production data on ${ }^{4} \mathrm{He}$. The apparatus maintained LHe in the cell at $3.17 \mathrm{~K}$. Light heating was 


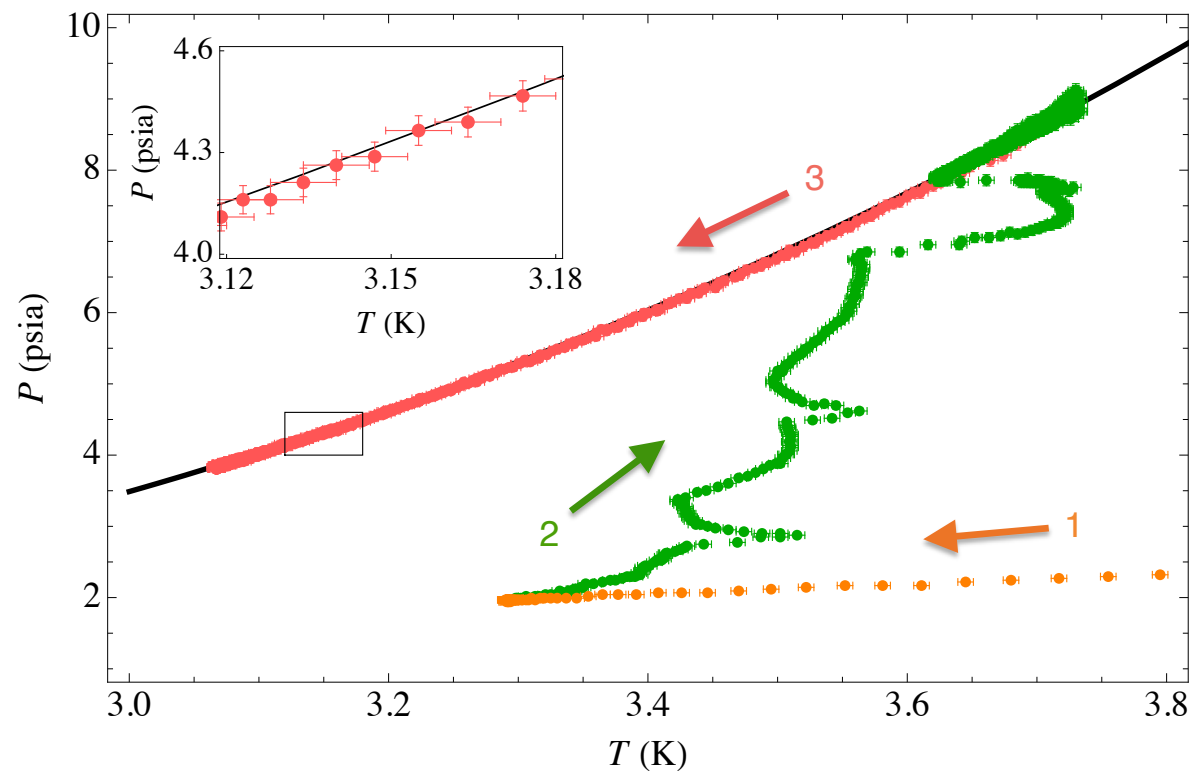

Figure 4: Measured vent line pressures and cell temperatures during LHe filling. Sequence of events: 1. Cooling the cell with exchange gas inside; 2. Adding more gas and filling the cell with liquid; 3 . Stopping the fill and allowing the liquid to cool to the base temperature. The black curve is the saturated vapor pressure of liquid helium as a function of temperature from Ref. [10]. Inset: Selected points along the SVP curve with visible error bars. 
applied to the second stage to test the system's ability to control temperature. A steady-state heater power of $160 \mathrm{~mW}$ kept the second stage $\approx 0.1 \mathrm{~K}$ above to a lesser degree.) When the liquid reached the very top of the cell, those 


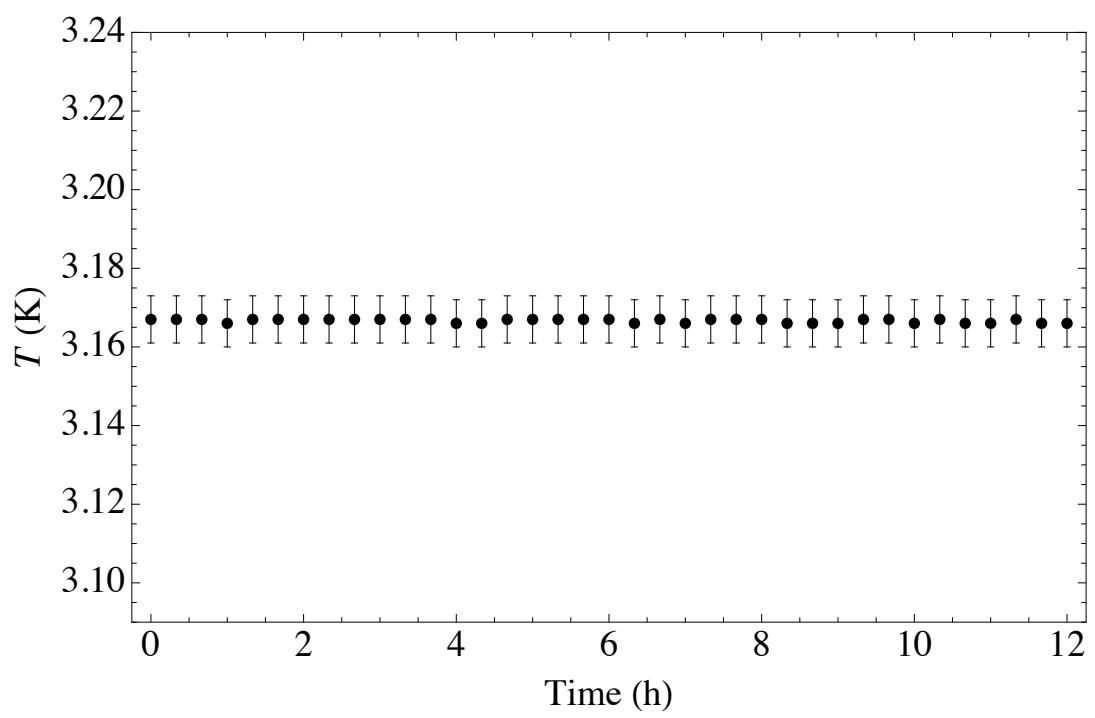

(a)

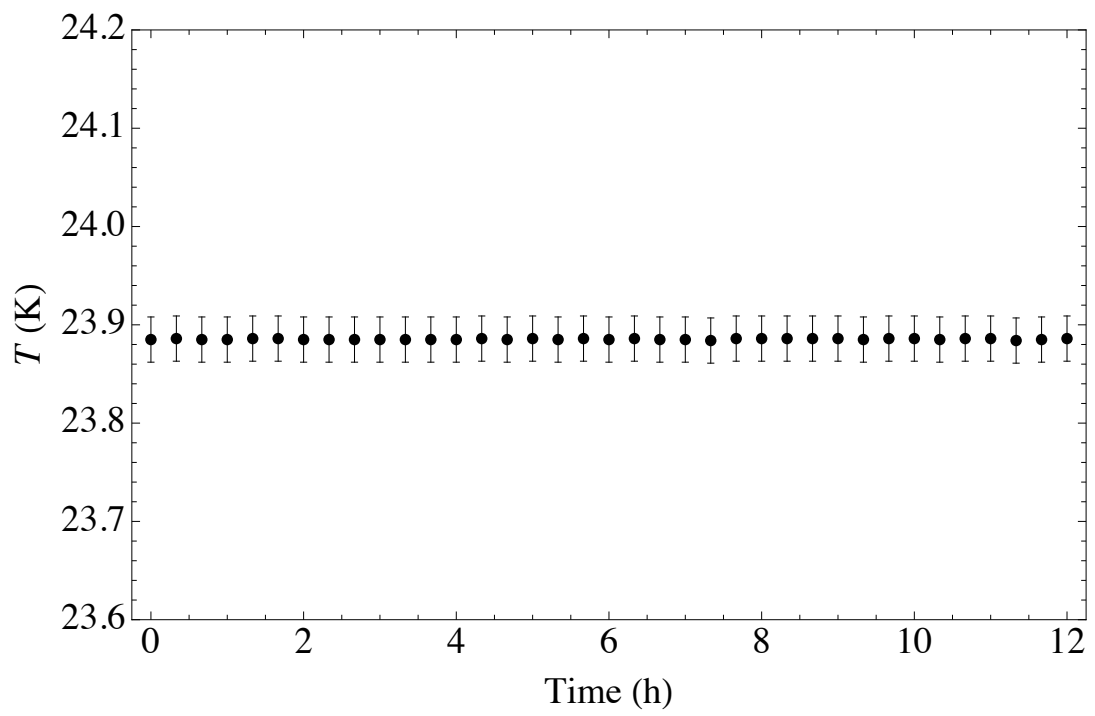

(b)

Figure 5: Measured liquid temperatures versus time. (a) For 12 hours of the LHe commissioning run, 6 days after filling the cell and (b) For 12 hours of production running on $\mathrm{LD}_{2}, 29$ days after filling the cell. The full temperature range on each y-axis corresponds to a $1 \%$ difference in liquid density. 
smaller-than-visible bubbles collected along the top seam and combined to form visible bubbles, which drifted to the outlet tube. From visual observation, the bubbles at the top were $\sim 1-3 \mathrm{~mm}$ in diameter. The liquid below remained clear to the naked eye.

Detailed studies of density corrections due to bubbling in $\mathrm{LH}_{2}$ and $\mathrm{LHe}$ were carried out in Refs. [13 15]. Their target cells were subject to higher heat fluxes, as evidenced by the observation of visible bubbles in the bulk liquid. It 245 is difficult to apply the method of Ref. [13] directly to our apparatus, since it relies on observations of those bubbles in the bulk. We can, however, use their results to set the scale for density corrections. For example, Ref. [14] applied a density correction of $0.5 \%$ with bubbles in the $\mathrm{LH}_{2}$ ranging in size from $0.3-$ $3 \mathrm{~mm}$. Ref. [15] reported density corrections of $<0.05 \%$ with $0.3 \mathrm{~mm}$ diameter 250 bubbles in the bulk LHe.

In Refs. [13, 14, the production of boil-off vapor was measured by closing a valve on the cell outlet to build pressure and then observing the time taken to empty the target, similar to the Full/Empty valve described in Section 2.3 It took 7 minutes to empty their $1.5 \mathrm{~L}$ cell of $\mathrm{LH}_{2}$ after closing the valve, for a volumetric rate of vapor production of $3.6 \mathrm{~cm}^{3} / \mathrm{s}$. In our apparatus, it took 1 hour to empty the $285 \mathrm{~cm}^{3}$ cell of LHe, for a vapor production rate of $0.08 \mathrm{~cm}^{3} / \mathrm{s}$. (During this test we did not apply any additional heating to speed the emptying process.) Given the scale of these corrections, the bubbles in our liquid have a negligible effect on the density.

260

In principle, we could suppress bubbles by subcooling — building pressure above the liquid and cooling below the boiling point at that particular pressure. To achieve this, we could completely fill the condenser with liquid, which interrupts the convective loop and raises the liquid level to warmer sections of the fill and vent tubing. This would, however, remove the ability to cycle quickly 


\subsection{Temperature gradients}

As described in Sections 2.4 and 4.3 , the liquid in the cell is subjected to background heating, largely from thermal radiation and residual gas accommodation. This heat is carried off by the convective loop. In addition to the factorycalibrated thermometer inserted into the bottom of the cell, there is a second thermometer ${ }^{10}$ (calibrated in-house) which is inserted into the top of the cell. Both thermometers were immersed in liquid during the run. The temperature difference between top and bottom was $\approx 100 \mathrm{mK}$. This corresponds to a $0.7 \%$ difference in density in LHe at $3.2 \mathrm{~K}$.

\section{5. $\mathrm{LD}_{2}$ Operation}

We have taken 600 hours of production data with $\mathrm{LD}_{2}$ in the cell at $24 \mathrm{~K}$. Liquid was held in the cryostat over two separate month-long runs. Once per week, we used the Full/Empty valve to transfer the liquid to the reservoir for background studies. In "empty" mode, the cold gas reached a steady-state temperature of $31 \mathrm{~K}$. Cell temperatures, both full and empty, recorded during one of the runs are shown in Fig. 6. The liquid temperature was stable during both runs; a representative sample is shown in the bottom panel of Fig. 5 Liquid temperature fluctuations were small compared to the temperature sensor uncertainty $( \pm 23 \mathrm{mK}$ at $24 \mathrm{~K})$. For a sense of scale, in $\mathrm{LD}_{2}$ at $24 \mathrm{~K}$, a $50 \mathrm{mK}$ change in temperature corresponds to a difference in density of $<0.1 \%$.

Additional safety measures were required for $\mathrm{D}_{2}$ operation since the gas can form a flammable mixture in air over a wide range of concentrations (4-75\%). These included: (1) a storage tank and relief path to isolate the flammable gas from air, (2) a dedicated $\mathrm{H}_{2} / \mathrm{D}_{2}$ vent with spark-resistant blower to remove gas safety during emergency venting, (3) replacing the original pressure gauge with an intrinsically safe model ${ }^{11}$ and (4) a series of safety interlocks and alarms. The relief paths to the $\mathrm{H}_{2} / \mathrm{D}_{2}$ vent are depicted in Fig. 3 .

\footnotetext{
${ }^{10}$ Lake Shore CX-1050-SD-HT

${ }^{11}$ Ashcroft A4SAM0442D160A
} 


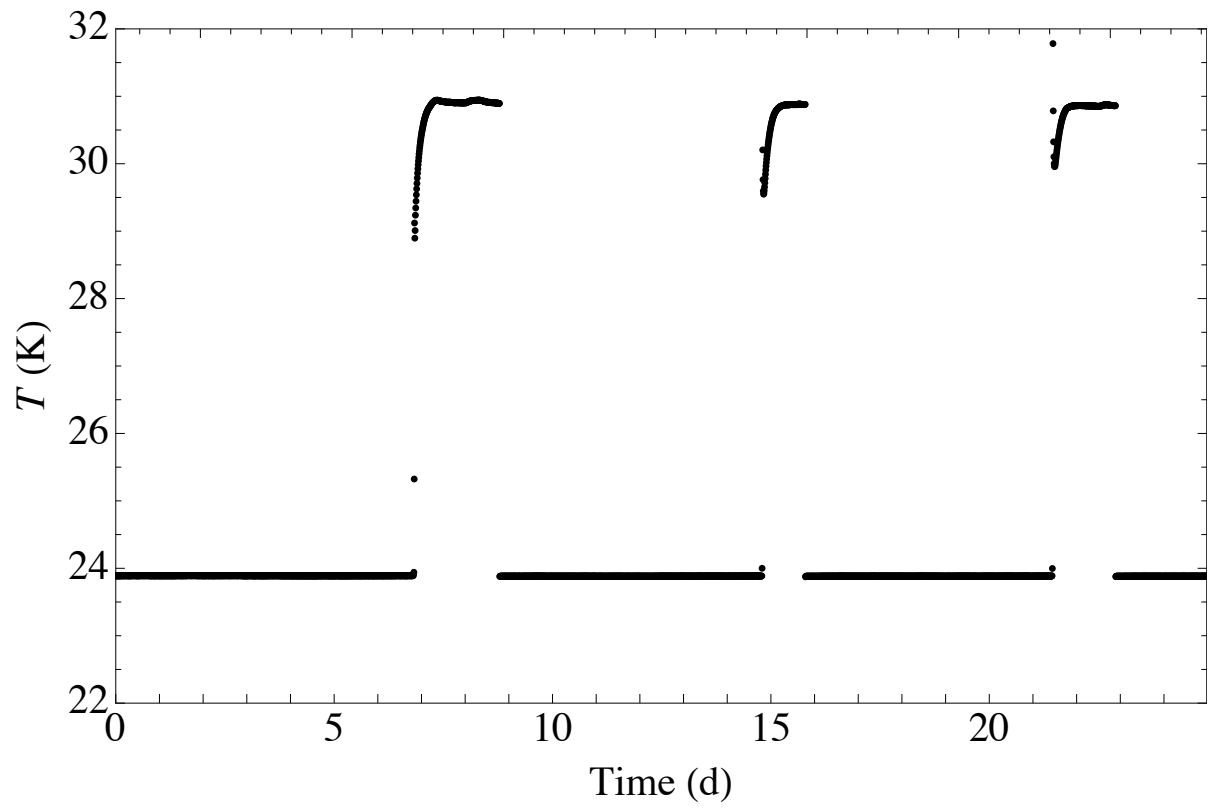

Figure 6: Measured target cell temperatures versus time during one $\mathrm{LD}_{2}$ production run. The cell was emptied of liquid once per week for background studies. During these periods cold gas remained in the cell at $T=31 \mathrm{~K}$. 
Bubbles along the top of the cell during $\mathrm{LD}_{2}$ running were noticably smaller than those observed in LHe. There were still no visible bubbles in the body of the cell. Reduced vapor production is expected in $\mathrm{LD}_{2}$ due to its higher latent heat of vaporization (see Table 1). Indeed it took considerably longer to empty the cell without heating: $\sim 4$ hours, as opposed to 1 hour with LHe. Any density correction due to bubbling is negligible.

Temperature gradients were comparable to those observed during the LHe ature difference was $64 \mathrm{mK}$. The density of $\mathrm{LD}_{2}$ at $24 \mathrm{~K}$ does not vary strongly with temperature, so this corresponds to a difference of only $0.1 \%$.

\subsection{Para-ortho conversion}

There are two "types" of $\mathrm{D}_{2}$ molecules, ortho and para, which are differentiated a given sample affects its physical properties, including the density. At room temperature, the so-called "normal" concentrations are $66.7 \%$ ortho and $33.3 \%$ para. At $20 \mathrm{~K}$, the "equilibrium" concentrations are $97.8 \%$ ortho and $2.2 \%$ para. (Note: There are also normal and equilibrium forms of $\mathrm{H}_{2}$, though with different naming conventions and concentrations.)

Natural conversion of $\mathrm{D}_{2}$ (i.e. without a catalyst) is extremely slow; it would take almost a year to fully convert the liquid from normal- to equilibrium- $\mathrm{D}_{2}$ [16. Since our runs at $\mathrm{HI} \gamma \mathrm{S}$ are on the order of a month, we use the density of $\mathrm{n}-\mathrm{D}_{2}$ throughout. The natural conversion rate in $\mathrm{LH}_{2}$ is over 30 times faster, so we cannot just treat it as normal $\mathrm{H}_{2}$ for an entire run. That said, this is a very small effect: at $20 \mathrm{~K}$, the difference in densities between $\mathrm{n}-\mathrm{H}_{2}$ and $\mathrm{e}-\mathrm{H}_{2}$ is $\approx 0.2 \%[7$.

\section{Summary}

We have designed, constructed, and operated a cryogenic target capable of liq320 uefying ${ }^{4} \mathrm{He}, \mathrm{H}_{2}$, and $\mathrm{D}_{2}$. Studies of the uncertainties due to bubbling, thermal gradients, etc., in both $\mathrm{LHe}$ and $\mathrm{LD}_{2}$ yield a total uncertainty in target 
thicknesses of $1 \%$. A low-temperature valve enables rapid cycling of the target between full and empty modes.

The cryogenic target is a key component in a series of nuclear Compton for measurements of the proton polarizabilities.

\section{Acknowledgements}

The authors wish to thank the Polarized Target Group at Jefferson Lab for their generous advice on the design of the Kapton cell and circulation loop. Thanks $\mathrm{H}_{2} / \mathrm{D}_{2}$ safety system.

This work was supported by US Department of Energy contracts DE-FG0297ER41033, DE-FG02-06ER41422, and DE-SCOO0536.

\section{References}

[1] H. Grießhammer, J. McGovern, D. Phillips, G. Feldman, Progress in Particle and Nuclear Physics 67 (2012) 841-897.

[2] E. Bielert, et al., Nuclear Instruments and Methods in Physics Research Section A 746 (2014) 20-25. 
[3] H. Ryuto, et al., Nuclear Instruments and Methods in Physics Research Section A 555 (2005) 1-5.

[4] B. MacGibbon, Ph.D. thesis, University of Illinois (1995).

[5] T. Glebe, Ph.D. thesis, University of Göttingen (1996).

[6] S. Santra, et al., Nuclear Instruments and Methods in Physics Research Section A 620 (2010) 421-436.

355 [7] E. Lemmon, M. McLinden, D. Friend, Thermophysical Properties of Fluid Systems, in: P. Linstrom, W. Mallard (Eds.), NIST Chemsitry WebBook, NIST Standard Reference Database Number 69, National Institute of Standards and Technology, Gaithersburg, MD, http://webbook.nist.gov (retrieved June 2, 2016).

[8] F. Pobell, Matter and Methods at Low Temperatures, Springer, Berlin, 2007.

[9] M. Berger, et al., XCOM: Photon Cross Section Database, National Institute of Standards and Technology, Gaithersburg, MD, http://physics.nist.gov/xcom (retrieved April 11, 2013).

365 [10] R. Donnelly, C. Barenghi, Journal of Physical and Chemical Reference Data 27 (1998) 1217-1274.

[11] P. Schmidt-Wellenburg, O. Zimmer, Cryogenics 46 (2006) 799-803.

[12] B. Louie, W. Steward, Advances in Cryogenic Engineering 35 (1990) 403412.

[13] M. Tate, M. Sadler, Nuclear Instruments and Methods 204 (1983) 295-298.

[14] M. Sadler, et al., Physical Review D 35 (1987) 2718-2735.

[15] B. Nilsson, Ph.D. thesis, Lund University (2003).

[16] P. Souers, Hydrogen Properties for Fusion Energy, University of California Press, Berkeley, 1986. 